\title{
Hydrothermal Deposition as a Novel Method for the Preparation of Co-Mn Mixed Oxide Catalysts Supported on Stainless Steel Meshes: Application to VOC Oxidation
}

\section{Pavel Topka ( $\nabla$ topka@icpf.cas.cz )}

Institute of Chemical Process Fundamentals of the CAS https://orcid.org/0000-0002-8122-2830

Květuše Jirátová

ICPF CAS: Ustav chemickych procesu Akademie Ved Ceske Republiky

Michaela Dvořáková

UCT Prague: Vysoka skola chemicko-technologicka v Praze

Jana Balabánová

ICPF CAS: Ustav chemickych procesu Akademie Ved Ceske Republiky

Martin Koštejn

ICPF CAS: Ustav chemickych procesu Akademie Ved Ceske Republiky

František Kovanda

UCT Prague: Vysoka skola chemicko-technologicka v Praze

\section{Research Article}

Keywords: Cobalt-manganese mixed oxides, Structured catalysts, Hydrothermal reaction, Stainless steel meshes, Ethanol total oxidation, Volatile organic compounds

Posted Date: June 15th, 2021

DOI: https://doi.org/10.21203/rs.3.rs-566024/v1

License: (9) This work is licensed under a Creative Commons Attribution 4.0 International License. Read Full License

Version of Record: A version of this preprint was published at Environmental Science and Pollution Research on August 21st, 2021. See the published version at https://doi.org/10.1007/s11356-021-15906y. 


\section{Abstract}

The aim of this work was to develop a novel method for the preparation of structured Co-Mn mixed oxide catalysts: deposition on stainless steel meshes by hydrothermal synthesis. The use of meshes enabled the deposition of a thin layer of the active phase, which significantly suppressed the influence of internal diffusion. Consequently, the prepared catalysts exhibited from 48 to 114 times higher catalytic activity in ethanol oxidation than the commercial pelleted Co-Mn-Al catalyst. Moreover, we have shown that their catalytic activity correlated with the amount of surface oxygen vacancies determined by XPS. Finally, the outstanding activity of the catalyst with Co:Mn ratio of 0.5 was ascribed to the mutual effect of high number of oxygen vacancies and exceptional redox properties.

\section{Introduction}

Catalysts supported on stainless-steel meshes are flexible to be fit into any kind of reactor, while ensuring a low pressure drop and good heat transfer (Cybulski \&Moulijn, 2006). Moreover, thin film of active phase deposited on metal meshes enables its high utilization in catalytic reaction due to low influence of the internal diffusion of reactants and products (Jiratova et al., 2019). Cobalt and manganese oxides show high catalytic activity in various oxidation reactions and the catalysts supported on metal meshes can be applied in any kind of a reactor especially that designated for fast reactions (Dvořáková et al., 2019). The Co-Mn oxides were investigated as catalysts for the total oxidation of volatile organic compounds (VOC) using various compounds, such as ethyl acetate and n-hexane (Tang et al., 2014), ethanol (Jirátová et al., 2009), toluene (Lamonier et al., 2007), and propanol (Castaño et al., 2015).

The oxides of transition metals can easily change the oxidation state and work in redox cycle. $\ln \mathrm{Co}_{3} \mathrm{O}_{4}$, the presence of both divalent and trivalent Co cations and good oxygen mobility through spinel structure is promising to catalyze the redox reactions. Many manganese oxides with different crystal structures and $\mathrm{Mn}$ cations in various oxidation states can be found (e.g., $\mathrm{MnO}, \mathrm{Mn}_{3} \mathrm{O}_{4}, \mathrm{Mn}_{2} \mathrm{O}_{3}$, and $\mathrm{MnO}_{2}$ ). Several Co-Mn mixed oxides were reported depending on the ratio of cations present in the products. The $\mathrm{Co}_{2} \mathrm{MnO}_{4}$ spinel has cubic structure whereas the $\mathrm{Mn}_{2} \mathrm{CoO}_{4}$ one is tetragonal (Lee et al., 2014). According to the thermodynamic study of $\mathrm{Mn}_{1+x} \mathrm{CO}_{2-x} \mathrm{O}_{4}$, both phases coexist for $x$ between 0.3 and 0.9 . The single cubic phase is stable below this range and tetragonal phase is stable for $x>0.9$ (Aukrust \&Muan, 1963). Another mixed oxide phase is trigonal with chemical formula $\mathrm{Co}_{1-z} \mathrm{Mn}_{1+z} \mathrm{O}_{3}$ (Masi et al., 2015). Tang et al. prepared mixed oxide matched with XRD reference pattern $(\mathrm{Co}, \mathrm{Mn})(\mathrm{Mn}, \mathrm{Co}){ }_{2} \mathrm{O}_{4}$ (PDF 00-018-0410). This formula implies the uncertainty in occupation of the metal cations in tetrahedral and octahedral sites (Tang et al., 2014).

Various methods can be applied for preparation of Co-Mn mixed oxides. Masi et al. prepared the Co-Mn mixed oxides by high-energy ball milling of single oxide powders and observed the impact of mechanochemical treatment by in situ XRD analysis of samples after different time of milling (up to 100 hours); they observed presence of aforementioned phases (Masi et al., 2015). Liang et al. prepared mixed oxides by citric acid-assisted sol-gel method and by coprecipitation of aqueous nitrate solution with 
ammonium hydroxide, observing larger surface area for the samples prepared by sol-gel method (Liang et al., 1998). Other authors used coprecipitation to prepare Co-Mn-Al hydrotalcite-like precursors to achieve good metal dispersion and thermal stability of the catalyst (Castaño et al., 2015, Jirátová et al., 2009, Lamonier et al., 2007). Lee et al. prepared mixed oxide powders via auto-combustion method, using glycine as a fuel (Lee et al., 2014). Tang et al. used acetate alcoholic solutions that were dried and then calcined to prepare mixed oxides (Tang et al., 2014). However, such methods have several disadvantages, e.g. high amount of chemicals needed for synthesis and thus negative impact on the environment.

Therefore, a more interesting method of the Co-Mn mixed oxide preparation is hydrothermal treatment of $\mathrm{Co}$ and $\mathrm{Mn}$ salts in aqueous solutions under temperatures higher than $100^{\circ} \mathrm{C}$ and corresponding pressure. Variation of preparation conditions can change physical chemical properties of the prepared products and, in the presence of a structural support, affect properties of the arising layers (e.g., their composition, adhesion to the support, etc.). We have shown recently that structured cobalt oxide catalysts supported on stainless steel meshes can be easily prepared by hydrothermal synthesis under mild conditions (Topka et al., 2020). Besides, they exhibited good performance and selectivity in ethanol oxidation, which was employed as a model volatile organic coumpound. Due to the formation of thin film of the active phase and, consequently, the low influence of internal diffusion limitations, this catalyst was more active in ethanol oxidation than the pelletized commercial $\mathrm{Co}_{3} \mathrm{O}_{4}$ with 50 times higher content of cobalt oxide. We reported formerly (Kovanda et al., 2013) that the efficiency of cobalt oxide in ethanol oxidation can be enhanced by preparing Co-Mn mixed oxide catalysts. Cai et al. demonstrated that Mn introduction leads to increased surface $\mathrm{Co}^{2+}$ concentration and active oxygen, which contributed to high catalytic activity in VOC oxidation (Cai et al., 2015). In a recent study (Zhang et al., 2020), the introduction of Mn increased reducibility and catalytic performance of cobalt oxides. The Co-Mn oxide catalysts were more active in toluene oxidation than their $\mathrm{Co}-\mathrm{Ni}$ or $\mathrm{Co}-\mathrm{Cu}$ analogues. However, the structured $\mathrm{Co}-\mathrm{Mn}$ catalysts supported on stainless steel meshes were not studied yet.

The present work is focused on the preparation of structured $\mathrm{Co}-\mathrm{Mn}$ mixed oxide catalysts with various $\mathrm{Co} / \mathrm{Mn}$ molar ratios. The mixed oxides supported on stainless steel meshes were prepared by heating of carbonate precursors, which crystallized on the supports immersed in the aqueous solutions of Co and $\mathrm{Mn}$ nitrates during hydrothermal treatment in the presence of hydrolyzing urea. The physical-chemical properties of the catalysts were investigated by XRD, SEM, FTIR, $\mathrm{H}_{2}-\mathrm{TPR}$, and XPS. The catalytic activity of the prepared catalysts was examined in the total oxidation of ethanol and compared with that of the pelletized commercial Co-Mn-Al mixed oxide catalyst. The obtained physicochemical characteristics were correlated with activity and selectivity of the catalysts in ethanol oxidation, which was selected as a model reaction.

\section{Experimental}

\subsection{Catalysts preparation}


Circular stainless steel meshes (composition in wt. \% Fe 71, Cr 16, Ni 11, Mn 2, mesh size 0.40 mm, wire diameter $0.22 \mathrm{~mm}$ ) with outer diameter of $25 \mathrm{~mm}$ were used as supports. Before deposition, the meshes were cleaned mechanically using a brush with detergent, then thoroughly washed in distilled water and the cleaning process was finished by degreasing in acetone for $10 \mathrm{~min}$ in an ultrasonic bath. Finally, the meshes were dried at room temperature in air. The supported mixed oxides with various Co:Mn molar ratios were prepared as follows: The meshes were placed into $75 \mathrm{ml}$ of aqueous solution containing Co and $\mathrm{Mn}$ nitrates (total $\mathrm{Co}+\mathrm{Mn}$ concentration of $\left.0.10 \mathrm{~mol} \mathrm{I}^{-1}\right)$ and urea $\left(0.50 \mathrm{~mol} \mathrm{I}^{-1}\right)$. The deposition was performed under hydrothermal conditions at $140^{\circ} \mathrm{C}$ for $120 \mathrm{~h}$ using sealed $100 \mathrm{ml}$ Teflon lined stainless steel autoclaves. Then the meshes were taken out, rinsed with distilled water, dried at $60^{\circ} \mathrm{C}$, and heated at $500^{\circ} \mathrm{C}$ for $4 \mathrm{~h}$ in air. The samples were labelled according to their nominal $\mathrm{Co} /(\mathrm{Co}+\mathrm{Mn})$ molar ratios ( 0 , $0.2,0.4,0.5,0.6,0.8$, and 1.0), what means that pure Mn oxide is labeled as 0 , and pure Co oxide as 1.0. The pelletized commercial Co-Mn-Al mixed oxide catalyst (Astin 2-100, Czech Republic, Co:Mn:Al molar ratio of 4:1:1), labeled as Com, was used for comparison.

\subsection{Catalyst characterization}

Powder X-ray diffraction (XRD) patterns were recorded using a Bruker AXS D8 diffractometer with Co Ka radiation $(\lambda=0.179 \mathrm{~nm})$ in $2 \theta$ range $10-80^{\circ}$, step size $0.02^{\circ}$. The qualitative analysis was performed with a HighScore Plus 4.0 software package (PANanalytical).

Surface morphology of the mixed oxides particles deposited on the stainless steel supports was observed using scanning electron microscope Tescan FERA 3.

Contents of $\mathrm{Co}$ and $\mathrm{Mn}$ in the deposited oxides were determined using the following way: Small amounts of the solids were gained by brushing of the meshes immersed in a container placed in an ultrasonic bath and filled with acetone. After the drying, the obtained solids were analyzed by energy-dispersive X-ray spectroscopy (EDX, Quantax 200, Bruker).

Surface area of the catalysts was determined from the adsorption isotherms of physisorbed krypton as described elsewhere (Šolcová et al., 2011), using a specially designed stainless steel vessel for measurements of bulky catalysts (Topka et al., CZ308606) enabling measurements of the surfaces of large samples (<30 mm) in the device of ASAP, Micromeritics, USA.

FTIR (Fourier-transform infrared) spectrometer Avatar 360 (Nicolet) was used to measure infrared spectra of samples between 360 and $4000 \mathrm{~cm}^{-1}$ (resolution $1.93 \mathrm{~cm}^{-1}, 300$ scans, $1 \mathrm{~s}$ per scan). FTIR was used in a specular reflection mode to obtain spectra from the catalysts deposited on stainless steel meshes while pristine stainless steel mesh was used as a background. The spectrum of pelletized Co-Mn-Al mixed oxide catalyst was obtained in a common ATR mode when the pellet was crushed and the powder was pressed against the ZnSe crystal.

$\mathrm{H}_{2}$-TPR measurement was done using $10 \mathrm{~mol} . \% \mathrm{H}_{2}$ and $20^{\circ} \mathrm{C} \mathrm{min}{ }^{-1}$ temperature ramp. Changes in $\mathrm{H}_{2}$ concentration were detected with a catharometer. Reduction of the grained CuO (0.160-0.315 mm) was 
performed to calculate absolute values of the hydrogen consumed during reduction of the samples.

Surface elemental analysis was performed by X-ray Photoelectron Spectrometer Kratos ESCA 3400. As the samples were placed on a carbon tape, a carbon correction was not possible and all spectra were corrected to a metal bound oxygen $(529.6 \mathrm{eV})$. Shirley background was subtracted and elemental compositions of the layers were calculated from the corresponding areas.

\subsection{Catalytic experiments}

The catalysts were tested in the oxidation of $770 \mathrm{ppm}$ of ethanol in air at GHSV of $20 \mathrm{I} \mathrm{g}_{\mathrm{cat}}{ }^{-1} \mathrm{~h}^{-1}$ using a fixed-bed reactor; details are given elsewhere (Soukup et al., 2012). The $T_{50}$ temperature, at which $50 \%$ of ethanol conversion was achieved, was used to compare the performance of the catalysts. Catalytic activity of the active phase was assessed as $R_{200}$ (amount of ethanol converted per gram of oxides and hour at $\left.200^{\circ} \mathrm{C}\right)$. The $T_{90}\left(\mathrm{CO}_{2}\right)$ temperature, at which $90 \%$ conversion of ethanol to $\mathrm{CO}_{2}$ was achieved, was employed to compare the efficiency of the catalysts. The pelletized commercial Co-Mn-Al mixed oxide catalyst (Astin 2-100, Czech Republic, Co:Mn:Al molar ratio of 4:1:1) was tested under the same conditions for comparison.

\section{Results And Discussion}

\subsection{Chemical, structural and textural properties of the catalysts}

The XRD results confirmed that the precipitation of $\mathrm{Co}$ and $\mathrm{Mn}$ nitrates under hydrothermal conditions in the presence of hydrolyzing urea resulted in crystallization of $\mathrm{Co}$ and $\mathrm{Mn}$ carbonates on the supports. After calcination, the supported catalysts containing approximately $1-5 \mathrm{wt}$. $\%$ of active oxides deposited on the meshes were obtained (Table 1). Determination of the oxides composition by chemical analysis was difficult due to very low $\mathrm{Co}$ and $\mathrm{Mn}$ contents in the catalysts and simultaneous presence of $\mathrm{Mn}$ in the used stainless steel meshes. Therefore, the Co and Mn concentrations were determined by EDX in small amounts of the deposited oxides removed from the meshes by brushing. The $\mathrm{Co} /(\mathrm{Co}+\mathrm{Mn})$ molar ratios in the prepared catalysts were calculated; these values corresponded approximately to the nominal ones, i.e., to the $\mathrm{Co} /(\mathrm{Co}+\mathrm{Mn})$ molar ratios in the nitrate solutions used for the catalysts preparation (Table 1). 
Table 1

Physicochemical characteristics of the catalysts.

\begin{tabular}{|c|c|c|c|c|c|c|c|c|c|}
\hline $\begin{array}{l}\mathrm{Co} / \\
(\mathrm{Co}+ \\
\mathrm{Mn})^{\mathrm{a}}\end{array}$ & $\begin{array}{l}\text { Oxides } \\
\text { content } \\
\text { (wt.\%) }\end{array}$ & $\begin{array}{l}\text { Weight } \\
\text { Loss }^{b} \\
(\%)\end{array}$ & $\begin{array}{l}\mathrm{Co}^{\mathrm{C}} \\
\text { (at.\%) }\end{array}$ & $\begin{array}{l}\mathrm{Mn}^{\mathrm{C}} \\
\text { (at.\%) }\end{array}$ & $\begin{array}{l}\mathrm{Co} / \\
(\mathrm{Co}+ \\
\mathrm{Mn})^{\mathrm{c}}\end{array}$ & $\begin{array}{l}\text { Particle } \\
\text { size }^{d} \\
(\mu \mathrm{m})\end{array}$ & $\begin{array}{l}S_{\text {BET }} \\
\left(m^{2}\right. \\
\left.g_{\text {cat }}{ }^{-1}\right)\end{array}$ & $\begin{array}{l}\mathrm{S}_{\mathrm{BET}} \\
\left(\mathrm{m}^{2}\right. \\
\left.\mathrm{g}_{\text {oxides }}{ }^{-1}\right)\end{array}$ & $\begin{array}{l}\mathrm{H}_{2}- \\
\text { TPR }^{\mathrm{e}} \\
\left(\mathrm{mmol}^{-1}\right. \\
\left.\text { goxides }^{-1}\right)\end{array}$ \\
\hline 0 & 4.97 & 22.8 & - & - & 0 & 16 & 0.71 & 14.3 & 3.4 \\
\hline 0.2 & 3.28 & 22.5 & 8.1 & 31.6 & 0.20 & 15 & 0.38 & 11.6 & 3.0 \\
\hline 0.4 & 2.55 & 6.8 & 14.6 & 20.4 & 0.42 & $9-15$ & 0.27 & 10.6 & 3.5 \\
\hline 0.5 & 1.14 & 34.1 & 8.4 & 8.7 & 0.49 & 13 & 0.27 & 23.7 & 5.3 \\
\hline 0.6 & 2.95 & 29.2 & 23.7 & 19.1 & 0.55 & 4 & 0.48 & 16.3 & 5.1 \\
\hline 0.8 & 1.91 & 21.0 & 29.8 & 8.2 & 0.78 & $7-20$ & 0.49 & 25.7 & 6.0 \\
\hline 1.0 & 1.34 & 3.6 & - & - & 1 & 7 & 0.16 & 11.9 & 12.9 \\
\hline Com & $97.0^{f}$ & - & $61.5^{\mathrm{g}}$ & $14.0^{\mathrm{g}}$ & 0.8 & - & 85 & 88 & 5.2 \\
\hline \multicolumn{10}{|c|}{ a Nominal molar ratio } \\
\hline \multicolumn{10}{|c|}{${ }^{b}$ Weight loss after treatment in an ultrasonic bath related to the initial weight of the deposited oxides } \\
\hline \multicolumn{10}{|c|}{${ }^{\mathrm{c}}$ Determined by EDX } \\
\hline \multicolumn{10}{|c|}{${ }^{\mathrm{d}}$ Determined from SEM images } \\
\hline \multicolumn{10}{|c|}{ e Hydrogen consumption in the temperature range $25-500^{\circ} \mathrm{C}$, per gram of active phase } \\
\hline \multicolumn{10}{|c|}{${ }^{f}$ The Com catalyst contained 3 wt. $\%$ of graphite, which was added before pelletizing } \\
\hline${ }^{g}$ Dete & ned by $\mathrm{Cl}$ & mical ana & rsis & & & & & & \\
\hline
\end{tabular}

Adhesion of the deposited Co-Mn oxides to the stainless steel supports was examined by a simple test, when the catalysts samples immersed in acetone were treated in an ultrasonic bath for $10 \mathrm{~min}$. After drying, the weight loss was determined and related to the initial weight of the oxides in the catalysts. The obtained values are summarized in Table 1; the deposited oxides showed quite good adhesion to the support; weight losses varied from 4 to $34 \%$, the highest being found for the 0.5 sample and the lowest for the 1.0 sample containing only cobalt oxide.

Powder XRD analysis of the supported samples showed the diffraction peaks at about 51 and $60^{\circ} 2 \theta$ that corresponded to a $\mathrm{Fe}_{0.65} \mathrm{Cr}_{0.1} \mathrm{Ni}_{0.25}$ phase (PDF 04-019-2390). They were ascribed to the stainless steel 
support. In the samples obtained after hydrothermal treatment of the stainless steel meshes in the solutions containing only $\mathrm{Co}$ or $\mathrm{Mn}$ nitrates, powder XRD analysis showed presence of $\mathrm{CoCO}_{3}$ (spherocobaltite, PDF 04-008-8312) or $\mathrm{MnCO}_{3}$ (rhodochrosite, PDF 04-011-3971). In the catalyst precursors prepared in the solutions containing mixtures of $\mathrm{Co}$ and $\mathrm{Mn}$ nitrates, both $\mathrm{CoCO}_{3}$ and $\mathrm{MnCO}_{3}$ were found as distinct phases. Only $\mathrm{MnCO}_{3}$ diffraction lines were detected in the precursors with higher $\mathrm{Mn}$ content prepared using solutions with $\mathrm{Co} /(\mathrm{Co}+\mathrm{Mn})$ molar ratios of 0.2 and 0.4 . It is known that the $\mathrm{Co}$ and $\mathrm{Mn}$ cations are precipitated at slightly different $\mathrm{pH}$ values; $\mathrm{pH}$ of 7.5 and 8.5 were reported for precipitation of $\mathrm{Co}$ and $\mathrm{Mn}$ hydroxides in $0.01 \mathrm{~mol} \mathrm{I}^{-1}$ solutions, respectively (Cavani et al., 1991). Therefore, former precipitation of Co cations to create $\mathrm{CoCO}_{3}$ could be expected during urea hydrolysis resulting in gradual $\mathrm{pH}$ increase in the solutions.

After calcination, $\mathrm{CO}_{3} \mathrm{O}_{4}(04-005-4386)$ and $\mathrm{Mn}_{2} \mathrm{O}_{3}$ (PDF 04-008-6383) were identified in the powder XRD pattern of the 1.0 and 0 catalysts, which contained only single Co and Mn oxides (Fig. 1). However, the Co-Mn mixed oxides were formed after calcination though the Co and $\mathrm{Mn}$ carbonates crystallized as separated phases on the surface of stainless steel meshes during their interaction with aqueous solutions of $\mathrm{Co}$ and $\mathrm{Mn}$ nitrates in presence of hydrolyzing urea. In the samples with lower Mn content, an incorporation of $\mathrm{Mn}$ cations into $\mathrm{Co}_{3} \mathrm{O}_{4}$ spinel lattice or direct $\mathrm{CoMnO}_{3}$ formation could be anticipated. The pattern of the calcined 0.8 catalyst having relatively low $\mathrm{Mn}$ content contained $\mathrm{Co}_{3} \mathrm{O}_{4}$ accompanied by a cubic $\mathrm{Co}-\mathrm{Mn}$ mixed oxide corresponding to $\mathrm{Mn}_{1.9} \mathrm{Co}_{1.1} \mathrm{O}_{4}$ with spinel structure (PDF 04-009-3198) whereas $\mathrm{Co}_{3} \mathrm{O}_{4}$ together with $\mathrm{CoMnO}_{3}$ (PDF 03-065-3696) were identified in the 0.6 catalyst. The powder XRD patterns of the 0.5 and 0.4 catalysts showed only $\mathrm{CoMnO}_{3}$ as a crystalline mixed oxide deposited on the stainless steel support. Calcination of the precursors with low Co content prepared using solutions with $\mathrm{Co} /(\mathrm{Co}+\mathrm{Mn})$ molar ratios of 0.4 and 0.2 , in which $\mathrm{Co}$ and $\mathrm{Mn}$ carbonates were distinguished, led to transformation into various mixed oxides in dependence on Co and Mn contents. Only $\mathrm{CoMnO}_{3}$ was found in the 0.4 sample obtained from the precursor, in which $\mathrm{CoCO}_{3}$ diffraction lines were not detected; excess of $\mathrm{Mn}$ could be incorporated into an XRD-amorphous part. Tetragonal $\mathrm{Mn}_{2} \mathrm{CoO}_{4}$ spinel (PDF 04-007-4368) and $\mathrm{Mn}_{5} \mathrm{O}_{8}$ (PDF 04-008-3979) were found in the powder XRD pattern of the 0.2 catalyst with high Mn content. The powder X-ray pattern of the pelletized commercial catalyst (Com) is shown in the Supplementary material (Fig. S1). The catalyst contained a Co-Mn-Al mixed oxide with spinel structure. Slight amount of graphite (3 wt.\%) was added to the mixed oxide before pelletizing.

Summarizing, the $\mathrm{CoMnO}_{3}$ phase with rhombohedral ilmenite structure, indicating the presence of tetravalent Mn cations, was found in the $0.4,0.5$, and 0.6 catalysts (Fig. 1). Mixed oxides with spinel structure were detected in other Co-Mn catalysts; a non-perfect structure ordering with Co and Mn cations in various oxidation states could be expected in mixed oxides emerging after calcination of carbonate precursors at $500^{\circ} \mathrm{C}$ in oxidation environment (air).

In literature, slightly different composition was reported for the Co-Mn mixed oxides with Co:Mn molar ratio of $1: 1$ prepared by various methods. For example, Tang et al. prepared the $(\mathrm{Co}, \mathrm{Mn})(\mathrm{Mn}, \mathrm{Co})_{2} \mathrm{O}_{4}$ phase 
by decomposition of oxalates (Tang et al., 2014). Other authors reported a mixture of tetragonal $\mathrm{Mn}_{2} \mathrm{CoO}_{4}$ and cubic $\mathrm{MnCo}_{2} \mathrm{O}_{4}$ oxides when applied ball milling (Masi et al., 2015) or sol-gel combustion method (Lee et al., 2014). Difference in the phase compositions of the obtained oxides could be caused by thermal treatment; aforementioned authors used higher temperatures and longer times during thermal treatment, resulting in the formation of different oxide phases.

The surface morphology of the as-obtained catalysts is documented by SEM images in Fig. 2. The stainless steel meshes were covered with rather big particles of $\mathrm{Co}-\mathrm{Mn}$ oxides originating from crystals of carbonate precursors formed during hydrothermal reaction. The crystals of carbonate precursors had well-defined, roughly cubic shape (not shown here), which remained preserved after calcination. Sizes of the oxide particles changed in dependence on Co and Mn content (Table 1). The biggest particles with size of about $15 \mu \mathrm{m}$ were found in the 0 and 0.2 catalysts with high Mn content and decreased with increasing Co content in the deposited oxides. The particles with different sizes of about 9 and $15 \mu \mathrm{m}$ were observed in the SEM images of the 0.4 catalyst. Powder XRD pattern of this sample before calcination contained diffraction lines corresponding to $\mathrm{MnCO}_{3}$ only (Fig. 1) and thus, presence of an amorphous Co component, making the precursor crystallization more difficult, could be expected. The 0.5 catalyst contained more uniform particles with size of $13 \mu \mathrm{m}$ whereas the 0.6 sample showed the smallest particles $(4 \mu \mathrm{m})$. In comparison with the 0.6 catalyst, the 0.8 and 1.0 ones with high Co content showed larger particles (about $7 \mu \mathrm{m}$ ) but some considerably larger particles were also observed in the 0.8 catalyst.

The employed method of stainless steel coating with Co and Mn carbonate precursors led to crystallization of big particles with roughly cubic shape. Gradually increasing $\mathrm{pH}$ in the solution due to urea hydrolysis resulted in precipitation of $\mathrm{Co}$ and $\mathrm{Mn}$ cations and crystallization of tiny particles well adhering to the support surface, followed by growth of these particles with increasing reaction time; finally, well-defined big crystals were obtained. The conditions of hydrothermal reaction affect strongly size and morphology of the prepared products; for example, formation of urchin-like hierarchical CoMn ${ }_{2} \mathrm{O}_{4}$ nanostructures (Venkateswarlu et al., 2017), pseudo-spherical particles of $\mathrm{Co}_{3} \mathrm{O}_{4}$ and $\mathrm{Mn}_{\mathrm{x}} \mathrm{Co}_{3-\mathrm{x}} \mathrm{O}_{4}$ core-shell nanoparticles (Bian, 2018), or three-dimensional mesoporous $\mathrm{Co}_{3} \mathrm{O}_{4}$ flowers constructed by many nanoneedles (Liao et al., 2018) was reported.

All supported catalysts showed low surface area ranging from 0.16 to $0.71 \mathrm{~m}^{2} \mathrm{~g}^{-1}$ (calculated per gram of the catalyst, i.e. including the stainless steel meshes). For better comparison of the catalysts, their surface area was recalculated per gram of the active oxides (Co, Mn, and/or Co-Mn ones). The surface area of the active oxides changed from 11.6 to $25.7 \mathrm{~m}^{2} \mathrm{~g}^{-1}$ (Table 1).

The results of $\mathrm{H}_{2}$-TPR measurements obtained in the temperature range from 25 to $900^{\circ} \mathrm{C}$ are shown in Fig. 3 and Table 1. TPR profiles (Fig. 3) reflected various phase composition and Co and Mn contents in the catalysts. The 1.0 sample containing only $\mathrm{Co}_{3} \mathrm{O}_{4}$ showed one main reduction peak with $\mathrm{T}_{\max }$ at $395^{\circ} \mathrm{C}$ and a shoulder at somewhat lower temperature. This peak was ascribed to the reduction of $\mathrm{Co}^{3+}$ to $\mathrm{Co}^{2+}$ 
and $\mathrm{Co}^{2+}$ to $\mathrm{Co}^{0}$ (Calgaro \&Perez-Lopez, 2017, Lin \&Chen, 2004). Reduction of the 0 catalyst containing only $\mathrm{Mn}_{2} \mathrm{O}_{3}$ proceeded in two steps with temperature maxima at 355 and $442^{\circ} \mathrm{C}$. The reduction process included $\mathrm{Mn}_{3} \mathrm{O}_{4}$ as an intermediate; reduction of $\mathrm{MnO}_{2} / \mathrm{Mn}_{2} \mathrm{O}_{3}$ to $\mathrm{Mn}_{3} \mathrm{O}_{4}$ followed by reduction of $\mathrm{Mn}_{3} \mathrm{O}_{4}$ to $\mathrm{MnO}$ was reported (Kapteijn et al., 1994, Wu et al., 2016). The reduction of $\mathrm{MnO}_{2} / \mathrm{Mn}_{2} \mathrm{O}_{3}$ can proceed also in one step without $\mathrm{Mn}_{3} \mathrm{O}_{4}$ intermediate formation (Arena et al., 2001) depending on the conditions of TPR experiments. Incorporation of $\mathrm{Mn}$ into cobalt oxide manifested in broadening of temperature range, in which the reduction of the catalysts proceeded. The TPR experiments revealed reduction of some other mixed oxide components formed from carbonate precursors during calcination. The highest number of such components was observed with the 0.4 and 0.5 catalysts. Four distinguished peaks were observed in TPR profile of the 0.4 catalyst with $T_{\max }$ at $335,400,490$, and $593^{\circ} \mathrm{C}$. In the TPR profile of the 0.5 catalyst, the reduction peaks were overlapping and a hint of new low-temperature peak can be seen at $227^{\circ} \mathrm{C}$. This temperature maximum can be ascribed to the reduction of adsorbed oxygen species (Chen et al., 2017, Luo et al., 2018) and/or to $\mathrm{Co}^{4+}$ reduction, which can be formed by oxidation of surface $\mathrm{Co}^{3+}$ according to equation $1 / 2 \mathrm{O}_{2}+\mathrm{Co}^{3+} \rightarrow \mathrm{O}^{-}+h\left(\mathrm{Co}^{4+}\right)$, where $h$ is a positive hole, i.e., orbital without electron (Kaczmarczyk et al., 2016). The finding agrees well with the published values of $T_{\max }$ for $\mathrm{Co}^{4+}$ reduction at about $200^{\circ} \mathrm{C}$ (Jung et al., 2019). Reduction of the commercial Co-Mn-Al mixed oxide catalysts (the Com sample) proceeded in two temperature regions, the first between 100 and $500^{\circ} \mathrm{C}$ and the other between 500 and $900^{\circ} \mathrm{C}$. Both regions consist of some overlapping reduction peaks. Li et al. observed a similar TPR profile of $\mathrm{Co}-\mathrm{Mn}-\mathrm{Al}$ mixed oxide obtained at $500^{\circ} \mathrm{C}$ from a coprecipitated precursor ( $\mathrm{Li}$ et al., 2019).

The FTIR spectra of the examined catalysts are presented in Fig. 4. The spectra were taken in the range from 4000 to $400 \mathrm{~cm}^{-1}$ but their analysis was possible only in the range from 400 to $900 \mathrm{~cm}^{-1}$ due to interferences from the meshes forming artificial bands at wavenumbers higher than $900 \mathrm{~cm}^{-1}$. In the range from 400 to $900 \mathrm{~cm}^{-1}$, the stretching vibrations of metal-oxygen bonds can be found. Intensity of the bands is very low due to low concentration of active components in the supported catalysts; nevertheless, some interesting features can be recognized in the obtained spectra. Stretching vibrations at 554 and $659 \mathrm{~cm}^{-1}$ are typical for $\mathrm{Co}_{3} \mathrm{O}_{4}$ with spinel structure (Bentley et al., 1968, Jirátová et al., 2017). In the FTIR spectrum of the 1.0 catalyst, the bands 580,648 , and $667 \mathrm{~cm}^{-1}$ were observed. These bands correspond to $\mathrm{Co}_{3} \mathrm{O}_{4}$, with variations between $560-574 \mathrm{~cm}^{-1}$ for the first band and $659-661 \mathrm{~cm}^{-1}$ for the second one. The first band $v 1$ at $580 \mathrm{~cm}^{-1}$ was attributed to the spinel lattice vibrations connected with Co cations in octahedral sites. However, it seems that the first band is composed of more than one component. The second band $v 2$ at about $658 \mathrm{~cm}^{-1}$ was ascribed to vibrations of bonds between oxygen and Co in tetrahedral sites. The FTIR spectrum of the 0 catalyst containing only Mn oxide showed very broad but distinct band with maximum at $719 \mathrm{~cm}^{-1}$. This band can be attributed to the $\mathrm{Mn}-0$ bond (Dubal et al., 2010, Wu et al., 2017). In the Co-Mn mixed oxide catalysts, similar stretching vibrations of Co- $\mathrm{O}$ and $\mathrm{Mn}-\mathrm{O}$ bonds at 568 and $656 \mathrm{~cm}^{-1}$ were observed (Habibi \&Bagheri, 2017) and ascribed to the vibrations of Co cations in octahedral and tetrahedral oxygen environment related to the $\mathrm{Co}-\mathrm{O}$ and/or 
Mn-O bonds in spinels, respectively (Martin de Vidales et al., 1995, Ramachandran et al., 2015). The band at $860 \mathrm{~cm}^{-1}$ can be attributed to $\delta(\mathrm{C}-0)$ vibrations, coming likely from the rest of $\mathrm{MnCO}_{3}$ remaining in the catalysts even after calcination (Udayabhanu et al., 2017).

The surface composition in the near-surface region of the catalysts and chemical state of the elements were determined by XPS. As a carbon tape was used for fixing of the samples to a holder, it could manifest itself in a higher concentration of $\mathrm{C}$. Thus, the calibration of the spectra was carried out according to a metal bound oxygen $(529.6 \mathrm{eV})$. Binding energies of core level electrons are shown in the Supplementary material (Table S1) and the surface concentrations of the components are summarized in Table 2. In addition to the main components ( $\mathrm{Co}, \mathrm{Mn}, \mathrm{O})$ given in Table 2, Fe was also detected on the catalysts surfaces, likely coming from a slight erosion of stainless steel meshes during hydrothermal treatment in the solutions containing hydrolyzing urea.

Table 2

Surface composition of the catalysts (at. \%) determined by XPS.

\begin{tabular}{|llllll|}
\hline $\mathrm{Co} /(\mathrm{Co}+\mathrm{Mn})^{\mathrm{a}}$ & $\mathbf{C ~ 1 s}$ & $\mathbf{0 1 s}$ & Co 2p & Mn 2p & Fe 2p \\
\hline 0 & 47.77 & 37.97 & 0.00 & 12.76 & 1.50 \\
\hline 0.2 & 53.00 & 35.71 & 2.40 & 7.60 & 1.30 \\
\hline 0.4 & 56.92 & 32.51 & 4.35 & 4.41 & 1.82 \\
\hline 0.5 & 52.38 & 37.70 & 3.74 & 2.18 & 4.01 \\
\hline 0.6 & 58.38 & 33.10 & 5.18 & 2.73 & 0.62 \\
\hline 0.8 & 50.49 & 37.56 & 7.02 & 1.79 & 3.14 \\
\hline 1.0 & 66.04 & 28.41 & 3.38 & 0.00 & 2.16 \\
\hline a Nominal molar ratio & & & & \\
\hline
\end{tabular}

Deconvolution of the Co 2p, Mn 2p and 0 1s peaks is reported in Table 3. The Co 2p peak consisted of the two maxima, which corresponded to $\mathrm{Co}_{2} 2 \mathrm{p}_{1 / 2}$ and $\mathrm{Co}_{2} 2 \mathrm{p}_{3 / 2}$ orbitals. The spin-orbital splitting (15.2 \pm $0.05 \mathrm{eV}$ ) as well as broad satellite structure (Biesinger et al., 2011) points to the presence of $\mathrm{Co}^{2+}$ and $\mathrm{Co}^{3+}$ (Hagelin-Weaver et al., 2004). The peak at $780 \mathrm{eV}$ was assigned to tetrahedral $\mathrm{Co}^{2+}$, while the peaks at 781.3 and $783.5 \mathrm{eV}$ were ascribed to octahedral $\mathrm{Co}^{3+}$. This is in line with the literature data (Langell et al., 2000) and our earlier works (Chromčáková et al., 2015, Obalová et al., 2013, Obalová et al., 2007), although a reverse approach was also reported (lablokov et al., 2015).

Table 3. Deconvolution of Co 2p, Mn 2p and 0 1s peaks, molar ratios of $\mathrm{Co}^{2+} / \mathrm{Co}^{3+}, \mathrm{Mn}^{3+} / \mathrm{Mn}^{4+}$, and surface oxygen vacancies $\mathrm{O}_{\mathrm{v}} /(\mathrm{Co}+\mathrm{Mn})$ from XPS spectra. 


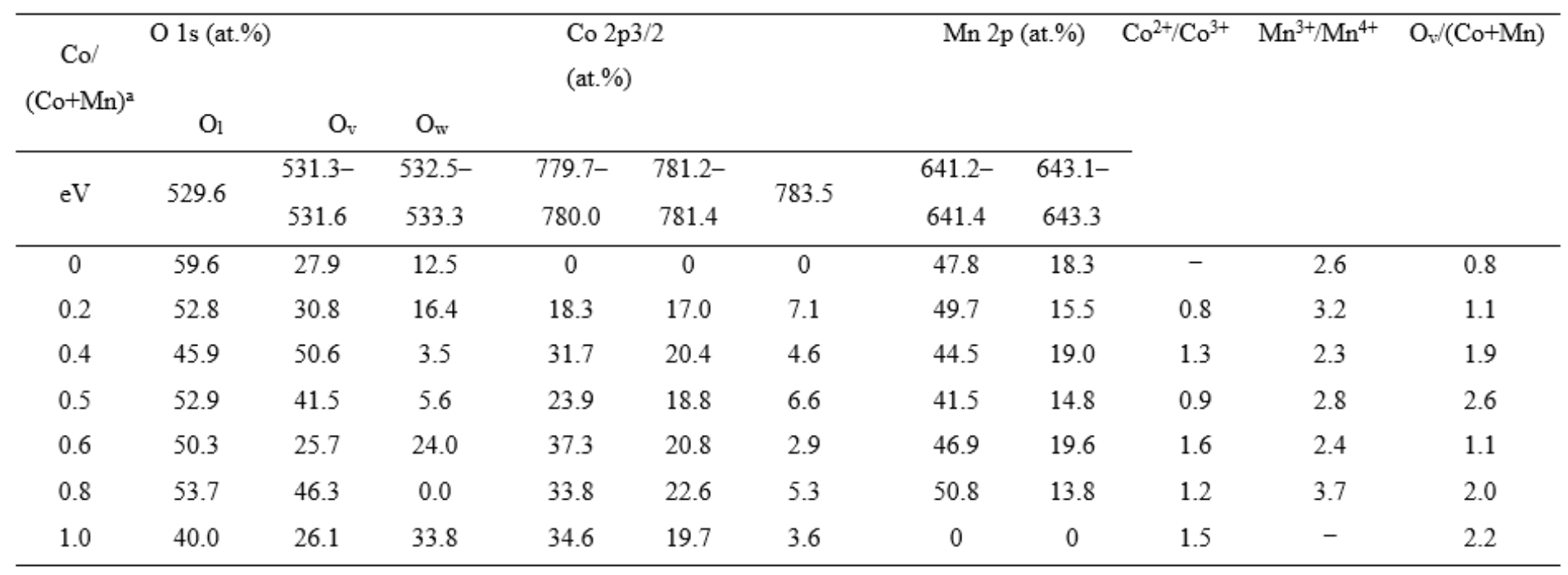

${ }^{a}$ Nominal molar ratio

The $\mathrm{Mn} 2 \mathrm{p}_{3 / 2}$ peak centered at 642.3-641.9 eV was ascribed to $\mathrm{Mn}_{3} \mathrm{O}_{4}$ and $\mathrm{MnO}_{2}$ ( $\mathrm{Kim}$ \&Shim, 2010). Determination of the manganese oxidation state was done as reported previously (Obalová et al., 2013, Pacultova et al., 2019). The $\mathrm{Mn} 2 \mathrm{p}_{3 / 2}$ spectrum was fitted by two peaks corresponding to $\mathrm{Mn}^{3+}$ (the component with lower binding energy) and $\mathrm{Mn}^{4+}$ (the component with higher binding energy). The $\mathrm{Mn}^{3+}$ ion is a strong oxidizing agent and its disproportionation to give $\mathrm{Mn}^{2+}$ and $\mathrm{MnO}_{2}$ is reported. Summarizing, based on the XPS results (Table 3 ) it can be concluded that $\mathrm{Mn}^{3+}$ is prevailing on the surface of the examined catalysts. The $\mathrm{Co}^{2+}$ is prevailing on the surface of most catalysts, with the exception of the 0.2 and 0.5 samples, where the concentration of $\mathrm{Co}^{3+}$ is higher by 20 or $10 \%$, respectively. Table 4shows a relation between the surface and bulk concentrations of the catalyst components. Compared to the bulk, surface of the examined catalysts is enriched with cobalt, which is mostly pronounced in the 0.5 catalyst. Surface concentration of manganese is suppressed, again mostly in the 0.5 catalyst. 
Table 4

Relative concentration (in \%) of Co and $\mathrm{Mn}$ in the catalysts determined

by EDX and XPS and relation of surface to bulk concentrations of individual components.

\begin{tabular}{|lllllll|}
\hline Co/(Co $+M n)^{a}$ & EDX & \multicolumn{3}{c}{ XPS } & \multicolumn{3}{c|}{ XPS/EDX } \\
\cline { 2 - 7 } & Co & Mn & Co & Mn & Co & Mn \\
\hline 0 & - & - & 0.00 & 100.00 & - & - \\
\hline 0.2 & 20.48 & 79.52 & 24.02 & 76.08 & 1.17 & 0.96 \\
\hline 0.4 & 41.51 & 58.49 & 49.71 & 50.40 & 1.20 & 0.86 \\
\hline 0.5 & 49.32 & 50.68 & 63.28 & 36.89 & 1.28 & 0.73 \\
\hline 0.6 & 55.31 & 44.69 & 65.57 & 34.56 & 1.19 & 0.77 \\
\hline 0.8 & 78.34 & 21.66 & 79.68 & 20.32 & 1.02 & 0.94 \\
\hline 1.0 & - & - & 99.71 & 0.00 & - & - \\
\hline a Nominal molar ratio & & & & & \\
\hline
\end{tabular}

The deconvolution of oxygen spectra revealed three peaks with binding energies of about $529.8,531.5$, and $533.0 \mathrm{eV}$. The first peak at $529.8 \mathrm{eV}\left(\mathrm{O}_{\mathrm{I}}\right)$ was attributed to the lattice oxygen in the metal oxides, the second $\mathrm{O}_{\mathrm{v}}$ centered at $531.5 \mathrm{eV}$ corresponded to the oxygen vacancies, and the third $\mathrm{O} w$ around $532.3 \mathrm{eV}$ was assigned to the hydroxyl species of surface adsorbed water (Feng et al., 2016, Wang et al., 2017). The number of oxygen vacancies belonging to $\mathrm{Co}$ and Mn oxides (Table 3) was calculated as the ratio of the oxygen vacancies $\mathrm{O}_{v}$ concentration to the sum of $\mathrm{Co}$ and $\mathrm{Mn}$ concentrations (in at. \%).

\subsection{Activity and selectivity in the ethanol total oxidation}

The prepared catalysts were tested in the total oxidation of ethanol. Ethanol conversions over the examined catalysts in dependence on reaction temperature are demonstrated in Fig. 5 and characteristic values describing catalytic activity and selectivity of the prepared catalysts are summarized in Table 5 . Temperatures $T_{50}$, at which $50 \%$ conversion of ethanol was achieved, varied in the range from $185^{\circ} \mathrm{C}$ for the 0.2 catalyst to $207^{\circ} \mathrm{C}$ for the 1.0 catalyst. The deposition of Co-Mn oxide thin layer enabled its high utilization in ethanol oxidation due to practically negligible influence of internal diffusion. Despite more than 85 times lower content of $\mathrm{Co}-\mathrm{Mn}$ oxides in the catalytic bed, the 0.2 catalyst exhibited practically the same catalytic performance in terms of $T_{50}$ as the commercial pelleted Co-Mn-Al catalyst (Table 5). Specific catalytic activity $R_{200}$, expressed as mmol of ethanol converted per gram of oxides and hour at $200^{\circ} \mathrm{C}$, was chosen to compare better the performance of examined catalysts containing various amounts of active Co-Mn oxides. The highest specific activity was found for the 0.5 catalyst, despite it showed slightly higher $T_{50}$ temperature than the 0.2 sample. In order to evaluate the stability of the 
supported catalysts with time on stream, four consecutive catalytic experiments were performed. While the $R_{200}$ of $34.2 \mathrm{mmol} \cdot \mathrm{g}_{\text {oxides }}{ }^{-1} \cdot \mathrm{h}^{-1}$ was achieved for the 0.5 catalyst in the first experiment, this value reached $35.9 \mathrm{mmol} \cdot \mathrm{g}_{\text {oxides }}{ }^{-1} \cdot \mathrm{h}^{-1}$ in the fourth experiment and the deactivation of the catalyst was not observed.

Table 5

Catalytic properties of the catalysts with various $\mathrm{Co} /(\mathrm{Co}+\mathrm{Mn})$ molar ratios deposited on stainless steel meshes compared to commercial Co-Mn-Al mixed oxide pellets (Com). Reaction conditions: 8 meshes in the bed, $770 \mathrm{ppm}$ of ethanol in air, reaction temperature increase $2^{\circ} \mathrm{C} \mathrm{min}{ }^{-1}$ from 50 to $400^{\circ} \mathrm{C}, \mathrm{GHSV} 20$

$$
\mathrm{Ig}^{-1} \mathrm{~h}^{-1} \text {. }
$$

\begin{tabular}{|lllllllll|}
\hline $\begin{array}{l}\mathrm{Co} / \\
(\mathrm{Co}+ \\
\mathrm{Mn})^{\mathrm{a}}\end{array}$ & $\begin{array}{l}T_{50} \\
\left({ }^{\circ} \mathrm{C}\right)\end{array}$ & $\begin{array}{l}T_{90}\left(\mathrm{CO}_{2}\right) \\
\left({ }^{\circ} \mathrm{C}\right)\end{array}$ & $\begin{array}{l}R_{200^{\mathrm{b}}} \\
\left(\mathrm{mmol}^{\mathrm{g}}\right.\end{array}$ & $\begin{array}{l}\mathrm{AcA}_{\max }{ }^{\mathrm{c}} \\
(\mathrm{ppm})\end{array}$ & $\begin{array}{l}\left.\mathrm{T}_{\max }{ }^{\mathrm{d}}{ }^{-1} \mathrm{~h}^{-1}\right) \\
\left({ }^{\circ} \mathrm{C}\right)\end{array}$ & $\begin{array}{l}\mathrm{CO}_{\max }{ }^{\mathrm{e}} \\
\left({ }^{\circ} \mathrm{C}\right)\end{array}$ & $\begin{array}{l}\mathrm{T}_{\max }{ }^{\mathrm{f}} \\
\left({ }^{\circ} \mathrm{C}\right)\end{array}$ & $\begin{array}{l}\text { Relative } \\
\text { activity }^{\mathrm{g}}\end{array}$ \\
\hline 0 & 200 & 248 & 6.7 & 485 & 226 & 37 & 245 & 22 \\
\hline 0.2 & 185 & 244 & 14.5 & 566 & 217 & 95 & 236 & 48 \\
\hline 0.4 & 195 & 251 & 14.7 & 601 & 227 & 149 & 249 & 49 \\
\hline 0.5 & 195 & 253 & 34.2 & 609 & 225 & 163 & 256 & 114 \\
\hline 0.6 & 194 & 264 & 15.0 & 506 & 221 & 108 & 235 & 50 \\
\hline 0.8 & 189 & 254 & 23.6 & 619 & 221 & 156 & 247 & 79 \\
\hline 1.0 & 207 & 260 & 20.6 & 579 & 243 & 76 & 261 & 69 \\
\hline $\mathrm{Com}$ & 189 & 353 & 0.3 & 20 & 164 & 0 & - & 1 \\
\hline
\end{tabular}

a Nominal molar ratio

${ }^{b}$ Catalytic activity in mmol of ethanol converted per gram of oxides and hour at $200^{\circ} \mathrm{C}$

${ }^{c}$ Maximum concentration of acetaldehyde during the experiment

d Temperature at which the maximum concentration of acetaldehyde was achieved

e Maximum concentration of carbon monoxide during the experiment

${ }^{\mathrm{f}}$ Temperature at which the maximum concentration of carbon monoxide was achieved

g Catalytic activity in terms of $R_{200}$ related to that of the Com catalyst 
Typical evolution of reaction byproducts during ethanol oxidation is shown in Fig. 6. Acetaldehyde was detected as the main byproduct of ethanol oxidation over all supported catalysts. Maximum acetaldehyde concentrations over the supported catalysts were achieved at the temperatures ranging from 217 to $243^{\circ} \mathrm{C}$ and varied from $485 \mathrm{ppm}$ for the 0 catalyst to $619 \mathrm{ppm}$ for the 0.8 one (Table 5). Evolution of acetaldehyde over the pelleted Co-Mn-Al mixed oxide catalyst (the Com sample) was considerably lower (up to $20 \mathrm{ppm}$ only) and the maximum of its formation occurred at lower temperature $\left(164^{\circ} \mathrm{C}\right)$. The maximum evolution of $\mathrm{CO}$ was found over the most active 0.5 catalyst (163 ppm), while no $\mathrm{CO}$ was detected over the Com catalyst. Importantly, the $\mathrm{T}_{90}\left(\mathrm{CO}_{2}\right)$ temperature needed to attain $90 \%$ conversion of all carbon components to carbon dioxide was much lower with the supported catalysts (from 244 to $260^{\circ} \mathrm{C}$ ) than with the Com sample $\left(353^{\circ} \mathrm{C}\right)$.

A strong interaction between $\mathrm{Co}$ and $\mathrm{Mn}$ components in the Co-Mn mixed oxide catalysts was confirmed by $\mathrm{H}_{2}$-TPR (Fig. 3). Incorporation of Mn changed reduction behavior of the cobalt oxide. While the 1.0 catalyst exhibited the reduction maximum at $395^{\circ} \mathrm{C}$ and the 0 catalyst containing only Mn oxide showed low-temperature maximum at $355^{\circ} \mathrm{C}$, enhanced reducibility was observed for the supported $\mathrm{Co}-\mathrm{Mn}$ mixed oxides. The $\mathrm{H}_{2}$-TPR profiles of $0.2,0.4,0.6$, and 0.8 samples revealed shift of the lowtemperature maximum reduction to $335^{\circ} \mathrm{C}$. Furthermore, the 0.5 catalyst exhibited a shoulder at about $227^{\circ} \mathrm{C}$, which was tentatively ascribed to reduction of $\mathrm{Co}^{4+}$ components (Mitran et al., 2020). Thus, the high catalytic activity of the 0.5 catalyst could be connected with its improved reduction behavior. It was reported recently that the reduction of Co-Mn mixed oxides occurs in two steps (Bulavchenko et al., 2018). In the first step, $(\mathrm{Mn}, \mathrm{Co})_{3} \mathrm{O}_{4}$ is reduced to form $(\mathrm{Mn}, \mathrm{Co}) \mathrm{O}$ solid solutions; $\mathrm{Co}_{2} \mathrm{MnO}_{4}$ oxide starts to be reduced to $\mathrm{Co}_{0.6} \mathrm{Mn}_{0.4} \mathrm{O}$ first and then $\mathrm{Mn}$-rich $\mathrm{Mn}_{2} \mathrm{CoO}_{4}$ is transformed into $\mathrm{Mn}_{0.6} \mathrm{Co}_{0.4} \mathrm{O}$. In the second step, the (Mn,Co)O solid solutions are reduced to metallic cobalt and $\mathrm{MnO}$. Similar behavior can be observed for other Co-Mn oxide catalysts.

We reported previously a good correlation between $\mathrm{H}_{2}$-TPR profiles and performance of the catalysts in ethanol oxidation (Gaálová et al., 2019, Topka et al., 2019, Topka \&Klementová, 2016). The abovementioned correlation of catalysts reducibility with catalytic performance of Co-Mn mixed oxide catalysts points to the redox (Mars - van Krevelen) reaction mechanism. This idea is supported by the XPS results shown in Fig. 7. They indicate that, regardless of the catalyst composition, the catalytic activity (shown here as relative to the Com catalyst) correlates with the amount of surface oxygen vacancies. Surface oxygen vacancies have been recently reported to play a crucial role in VOC oxidation (Lin et al., 2018, Yang et al., 2019). These defect sites on the surface of metal oxides adsorb oxygen from the air and transform it into catalytically active species. Similarly to our results, Mitran et al. recently observed that replacing of $\mathrm{Co}^{3+}$ with $\mathrm{Mn}^{4+}$ in Co-Mn oxides up to $\mathrm{Mn}_{0.15} \mathrm{Co}_{2.85}$ leads to the formation of active sites for ethanol oxidation (Mitran et al., 2020). Interaction of $\mathrm{Co}^{3+}$ and $\mathrm{Mn}^{4+}$ with lattice oxygen created oxygen vacancies, which served as catalytically active sites.

\section{Conclusions}


Precipitation of $\mathrm{Co}$ and $\mathrm{Mn}$ nitrates in the presence of hydrolyzing urea under hydrothermal conditions resulted in crystallization of $\mathrm{Co}$ and $\mathrm{Mn}$ carbonates on the surface of stainless steel meshes; supported catalysts containing 1.1-5 wt. \% of Co-Mn mixed oxides were obtained after calcination of the carbonate precursors at $500^{\circ} \mathrm{C}$ in air. In ethanol oxidation, the supported catalysts exhibited catalytic performance comparable to the pelleted commercial Co-Mn-Al mixed oxide catalyst. However, their catalytic activity, related to the content of active Co and Mn components, was 48-114 times higher. Regardless of catalysts composition, their catalytic activity correlated with the amount of surface oxygen vacancies determined by XPS. Outstanding catalytic activity was revealed for the catalyst with $\mathrm{Co} /(\mathrm{Co}+$ $\mathrm{Mn}$ ) molar ratio of 0.5 , which contained only $\mathrm{CoMnO}_{3}$ as a crystalline phase. This catalyst showed the best redox properties in the $\mathrm{H}_{2}$-TPR measurements and the highest amount of surface oxygen vacancies determined by XPS.

In comparison with the pelletized commercial Co-Mn-Al mixed oxide catalyst, the supported $\mathrm{Co}-\mathrm{Mn}$ mixed oxide catalysts showed significantly lower temperature needed to obtain $90 \%$ conversion of ethanol to $\mathrm{CO}_{2}\left(244-260^{\circ} \mathrm{C}\right.$ vs. $\left.353^{\circ} \mathrm{C}\right)$. This is an important result because the primary goal of the catalytic reaction is complete $\mathrm{VOC}$ oxidation to carbon dioxide (and water) at as low temperature as possible. A decrease of about $100^{\circ} \mathrm{C}$ is important also from the economical point of view: lower operating temperature of a catalyst needed to obtain a complete reactant conversion to $\mathrm{CO}_{2}$ means lower operating cost.

The formation of byproducts, namely acetaldehyde and carbon monoxide, was observed over the supported Co-Mn mixed oxide catalyst; the maximum concentrations were detected at about $220-260^{\circ} \mathrm{C}$ in dependence on the catalysts composition. No acetaldehyde was identified at temperatures higher than $270^{\circ} \mathrm{C}$. In contrast, the pelletized commercial Co-Mn-Al mixed oxide catalyst exhibited only low acetaldehyde formation and no formation of carbon monoxide. It was very likely due to internal diffusion effects and, consequently, slower transfer and longer contact time of the reactant and reaction intermediates inside the pellets.

\section{Declarations}

\section{Ethics approval and consent to participate}

Not applicable.

Consent for publication

Not applicable.

Availability of data and materials

All data generated or analysed during this study are included in this published article and its supplementary material. 
Competing interests

The authors declare that they have no competing interests.

\section{Funding}

The authors thank the Czech Science Foundation for the financial support (project 21-04477S).

\section{Authors' contributions}

FK designed the study, supervised the synthesis and wrote part of the manuscript. KJ supervised the catalytic measurements and wrote part of the manuscript. MD prepared the catalysts. JB performed the catalytic tests. MK performed the characterization of the catalysts. PT wrote part of the manuscript and finalized the manuscript. All authors read and approved the final manuscript.

\section{References}

1. Arena F, Torre T, Raimondo C, Parmaliana A (2001) Structure and redox properties of bulk and supported manganese oxide catalysts. Phys Chem Chem Phys 3:1911-1917. https://doi.org/10.1039/b100091h

2. Aukrust E, Muan A (1963) Phase Relations in the System Cobalt Oxide-Manganese Oxide in Air. J Am Ceram Soc 46:511-511. https://doi.org/10.1111/j.1151-2916.1963.tb13790.x

3. Bentley FF, Smithson LD, Rozek AL (1968) Infrared Spectra and Characteristic Frequencies [equivalency Symbol] $700-300 \mathrm{Cm}-1$ : Collection of Spectra, Interpretation, and Bibliography. Interscience 1968

4. Bian N (2018) Investigations on Hydrothermally Synthesized Co304/MnxCo3-xO4 Core-Shell Nanoparticles. MSU Graduate Theses

5. Biesinger MC, Payne BP, Grosvenor AP, Lau LWM, Gerson AR, Smart RSC (2011) Resolving surface chemical states in XPS analysis of first row transition metals, oxides and hydroxides: $\mathrm{Cr}, \mathrm{Mn}, \mathrm{Fe}, \mathrm{Co}$ and Ni. Appl Surf Sci 257:2717-2730. https://doi.org/10.1016/j.apsusc.2010.10.051

6. Bulavchenko OA, Gerasimov EY, Afonasenko TN (2018) Reduction of double manganese-cobalt oxides: in situ XRD and TPR study. Dalton Trans 47:17153-17159. https://doi.org/10.1039/c8dt04137g

7. Cai T, Huang H, Deng W, Dai Q, Liu W, Wang X (2015) Catalytic combustion of 1,2-dichlorobenzene at low temperature over Mn-modified Co304 catalysts. Appl Catal B 166-167:393-405. https://doi.org/10.1016/j.apcatb.2014.10.047

8. Calgaro CO, Perez-Lopez OW (2017) Decomposition of methane over Co3-xAlxO4 ( $x=0-2)$ coprecipitated catalysts: The role of Co phases in the activity and stability. Int J Hydrogen Energy 42:29756-29772. https://doi.org/10.1016/j.ijhydene.2017.10.082 
9. Castaño MH, Molina R, Moreno S (2015) Cooperative effect of the Co-Mn mixed oxides for the catalytic oxidation of VOCs: Influence of the synthesis method. Appl Catal A 492:48-59. https://doi.org/10.1016/j.apcata.2014.12.009

10. Cavani F, Trifirò F, Vaccari A (1991) Hydrotalcite-type anionic clays: Preparation, properties and applications. Catal Today 11:173-301. https://doi.org/10.1016/0920-5861(91)80068-K

11. Cybulski A, Moulijn JA (2006) Structured catalysts and reactors. Taylor \& Francis, Boca Raton

12. Dubal DP, Dhawale DS, Salunkhe RR, Lokhande CD (2010) Conversion of Chemically Prepared Interlocked Cubelike Mn[sub 3]O[sub 4] to Birnessite MnO[sub 2] Using Electrochemical Cycling. J Electrochem Soc 157:A812. https://doi.org/10.1149/1.3428675

13. Dvořáková $M$, Perekrestov R, Kširová P, Balabánová J, Jirátová $K$, Maixner J, Topka P, Rathouský J, Koštejn M, Čada M, Hubička Z, Kovanda F (2019) Preparation of cobalt oxide catalysts on stainless steel wire mesh by combination of magnetron sputtering and electrochemical deposition. Catal Today 334:13-23. https://doi.org/10.1016/j.cattod.2019.03.008

14. Feng Z, Bao W, Xu X, Ma X, Zhan J, Yin Y (2016) Heteroepitaxial Growth of Well-Dispersed Co304 Nanocatalysts on Porous ZnO Nanoplates via Successive Hydrothermal Deposition. ChemNanoMat 2, 946-951. https://doi.org/10.1002/cnma.201600204

15. Gaálová J, Topka P, Kaluža L, Soukup K, Barbier J (2019) Effect of gold loading on ceria-zirconia support in total oxidation of VOCs. Catal Today 333:190-195. https://doi.org/10.1016/j.cattod.2018.04.005

16. Habibi MH, Bagheri P (2017) Spinel cobalt manganese oxide nano-composites grown hydrothermally on nanosheets for enhanced photocatalytic mineralization of Acid Black 1 textile dye: XRD, FTIR, FESEM, EDS and TOC studies. J Iran Chem Soc 14:1643-1649. https://doi.org/10.1007/s13738017-1104-2

17. Hagelin-Weaver HAE, Hoflund GB, Minahan DM, Salaita GN (2004) Electron energy loss spectroscopic investigation of $\mathrm{Co}$ metal, $\mathrm{CoO}$, and $\mathrm{Co} 3 \mathrm{O} 4$ before and after $\mathrm{Ar}+$ bombardment. Appl Surf Sci 235:420-448. https://doi.org/10.1016/j.apsusc.2004.02.062

18. Chen $H$, Yang M, Tao S, Chen $G$ (2017) Oxygen vacancy enhanced catalytic activity of reduced Co304 towards p-nitrophenol reduction. Appl Catal B 209:648-656. https://doi.org/10.1016/j.apcatb.2017.03.038

19. Chromčáková Ž, Obalová L, Kovanda F, Legut D, Titov A, Ritz M, Fridrichová D, Michalik S, Kuśtrowski P, Jirátová K (2015) Effect of precursor synthesis on catalytic activity of Co304 in N2O decomposition. Catal Today 257:18-25. https://doi.org/10.1016/j.cattod.2015.03.030

20. lablokov V, Barbosa R, Pollefeyt G, Van Driessche I, Chenakin S, Kruse N (2015) Catalytic CO Oxidation over Well-Defined Cobalt Oxide Nanoparticles: Size-Reactivity Correlation. ACS Catal 5:5714-5718. https://doi.org/10.1021/acscatal.5b01452

21. Jiratova K, Perekrestov R, Dvorakova M, Balabanova J, Topka P, Kostejn M, Olejnicek J, Cada M, Hubicka Z, Kovanda F (2019) Cobalt Oxide Catalysts in the Form of Thin Films Prepared by 
Magnetron Sputtering on Stainless-Steel Meshes: Performance in Ethanol Oxidation. Catalysts 9. https://doi.org/10.3390/catal9100806

22. Jirátová K, Mikulová J, Klempa J, Grygar T, Bastl Z, Kovanda F (2009) Modification of Co-Mn-Al mixed oxide with potassium and its effect on deep oxidation of VOC. Appl Catal A 361:106-116. https://doi.org/10.1016/j.apcata.2009.04.004

23. Jirátová K, Balabánová J, Kovanda F, Klegová A, Obalová L, Fajgar R (2017) Cobalt Oxides Supported Over Ceria-Zirconia Coated Cordierite Monoliths as Catalysts for Deep Oxidation of Ethanol and N2O Decomposition. Catal Lett 147:1379-1391. https://doi.org/10.1007/s10562-0172047-z

24. Jung DH, Umirov N, Kim T, Bakenov Z, Kim JS, Kim S-S (2019) Thermal and Structural Stabilities of LixCoO2 cathode for Li Secondary Battery Studied by a Temperature Programmed Reduction. Eurasian Chem-Technol J 21:3. https://doi.org/10.18321/ectj780

25. Kaczmarczyk J, Zasada F, Janas J, Indyka P, Piskorz W, Kotarba A, Sojka Z (2016) Thermodynamic Stability, Redox Properties, and Reactivity of Mn304, Fe304, and Co3O4 Model Catalysts for N2O Decomposition: Resolving the Origins of Steady Turnover. ACS Catal 6:1235-1246. https://doi.org/10.1021/acscatal.5b02642

26. Kapteijn F, Singoredjo L, Andreini A, Moulijn JA (1994) Activity and selectivity of pure manganese oxides in the selective catalytic reduction of nitric-oxide with ammonia. Appl Catal B 3:173-189. https://doi.org/10.1016/0926-3373(93)e0034-9

27. Kovanda F, Jiratova K, Ludvikova J, Raabova H (2013) Co-Mn-Al mixed oxides on anodized aluminum supports and their use as catalysts in the total oxidation of ethanol. Appl Catal A 464:181-190. https://doi.org/10.1016/j.apcata.2013.05.044

28. Lamonier J-F, Boutoundou A-B, Gennequin C, Pérez-Zurita MJ, Siffert S, Aboukais A (2007) Catalytic Removal of Toluene in Air over Co-Mn-Al Nano-oxides Synthesized by Hydrotalcite Route. Catal Lett 118:165-172. https://doi.org/10.1007/s10562-007-9196-4

29. Langell MA, Gevrey F, Nydegger MW (2000) Surface composition of MnxCo1-xO solid solution by Xray photoelectron and Auger spectroscopies. Appl Surf Sci 153:114-127. https://doi.org/10.1016/s0169-4332(99)00361-x

30. Lee SI, Hong J, Kim H, Son J-W, Lee J-H, Kim BK, Lee H, Yoon K (2014) Highly Dense Mn-Co Spinel Coating for Protection of Metallic Interconnect of Solid Oxide Fuel Cells. J Electrochem Soc 161:F1389-F1394. https://doi.org/10.1149/2.0541414jes

31. Li W, Yang S, Wang K, Tu S, Lu M, Wu P (2019) Evaluation of the physiochemical properties and catalytic performance of CuCoMnAl mixed oxides derived from layered double hydroxides precursors with different mole ratios of $\mathrm{Cu} / \mathrm{Co}$ on the oxidation of toluene. Reac Kinet Mech Cat 128:965-977. https://doi.org/10.1007/s11144-019-01676-9

32. Liang Q, Chen K, Hou W, Yan Q (1998) CO hydrogenation over nanometer spinel-type Co/Mn complex oxides prepared by sol-gel method. Appl Catal A 166:191-199. https://doi.org/10.1016/S0926860X(97)00255-X 
33. Liao F, Han X, Zhang Y, Xu C, Chen H (2018) Template-free hydrothermal synthesis of 3D hierarchical Co304 microflowers constructed by mesoporous nanoneedles. Mat Lett 215:179-182. https://doi.org/10.1016/j.matlet.2017.12.095

34. Lin H, Chen Y-W (2004) The mechanism of reduction of cobalt by hydrogen. Mater Chem Phys 85:171-175. https://doi.org/10.1016/j.matchemphys.2003.12.028

35. Lin X, Li S, He H, Wu Z, Wu J, Chen L, Ye D, Fu M (2018) Evolution of oxygen vacancies in MnOx-CeO2 mixed oxides for soot oxidation. Appl Catal B 223:91-102.

https://doi.org/10.1016/j.apcatb.2017.06.071

36. Luo Y, Zheng Y, Zuo J, Feng X, Wang X, Zhang T, Zhang K, Jiang L (2018) Insights into the high performance of Mn-Co oxides derived from metal-organic frameworks for total toluene oxidation. $J$ Hazard Mater 349:119-127. https://doi.org/10.1016/j.jhazmat.2018.01.053

37. Martin de Vidales JL, Vila E, Rojas RM, Garcia-Martinez O (1995) Thermal Behavior in Air and Reactivity in Acid Medium of Cobalt Manganese Spinels MnxCo3-x04 Synthesized at Low Temperature. Chem Mater 7:1716-1721. https://doi.org/10.1021/cm00057a022

38. Masi A, Bellusci M, Carlini M, McPhail S, Padella F, Reale P (2015) Mechanochemical Processing of Mn and Co Oxides: An Alternative Way to Synthesize Mixed Spinels for Protective Coating. J Am Ceram Soc 99:308-314. https://doi.org/10.1111/jace.13863

39. Mitran G, Chen S, Seo D-K (2020) Role of oxygen vacancies and Mn4+/Mn3 + ratio in oxidation and dry reforming over cobalt-manganese spinel oxides. Mol Catal 483:110704. https://doi.org/10.1016/j.mcat.2019.110704

40. Obalová L, Pacultová K, Balabánová J, Jirátová K, Bastl Z, Valášková M, Lacný Z, Kovanda F (2007) Effect of $\mathrm{Mn} / \mathrm{Al}$ ratio in Co-Mn-Al mixed oxide catalysts prepared from hydrotalcite-like precursors on catalytic decomposition of N2O. Catal Today 119:233-238. https://doi.org/10.1016/j.cattod.2006.08.027

41. Obalová L, Karásková K, Wach A, Kustrowski P, Mamulová-Kutláková K, Michalik S, Jirátová K (2013) Alkali metals as promoters in Co-Mn-Al mixed oxide for N2O decomposition. Appl Catal A 462463:227-235. https://doi.org/10.1016/j.apcata.2013.05.011

42. Pacultova K, Bilkova T, Klegova A, Karaskova K, Fridrichova D, Jiratova K, Kiska T, Balabanova J, Kostejn M, Kotarba A, Kaspera W, Stelmachowski P, Slowik G, Obalova L (2019) Co-Mn-Al Mixed Oxides Promoted by K for Direct NO Decomposition: Effect of Preparation Parameters. Catalysts 9. https://doi.org/10.3390/catal9070593

43. Ramachandran T, Naveen N, Sumithra s, Vishista k (2015) Investigation on spinel MnCo2O4 electrode material prepared via controlled and uncontrolled synthesis route for supercapacitor application. J Mater Sci 50. https://doi.org/10.1007/s10853-015-9132-8

44. Soukup K, Petráš D, Topka P, Slobodian P, Šolcová O (2012) Preparation and characterization of electrospun poly(p-phenylene oxide) membranes. Catal Today 193:165-171. http://dx.doi.org/10.1016/j.cattod.2012.03.019 
45. Šolcová O, Matějová L, Topka P, Musilová Z, Schneider P (2011) Comparison of textural information from argon(87 K) and nitrogen(77 K) physisorption. J Porous Mat 18:557-565. https://doi.org/10.1007/s10934-010-9409-x

46. Tang W, Wu X, Li S, Li W, Chen Y (2014) Porous Mn-Co mixed oxide nanorod as a novel catalyst with enhanced catalytic activity for removal of VOCs. Catal Comm 56:134-138. https://doi.org/10.1016/j.catcom.2014.07.023

47. Topka P, Klementová M (2016) Total oxidation of ethanol over Au/Ce0.5Zr0.502 cordierite monolithic catalysts. Appl Catal A 522:130-137. http://dx.doi.org/10.1016/j.apcata.2016.05.004

48. Topka P, Hejtmánek V, Cruz GJF, Šolcová O, Soukup K (2019) Activated Carbon from Renewable Material as an Efficient Support for Palladium Oxidation Catalysts. Chem Eng Technol 42:851-858. https://doi.org/10.1002/ceat.201800611

49. Topka P, Dvořáková $M$, Kšírová P, Perekrestov R, Čada $M$, Balabánová J, Koštejn $M$, Jirátová $K$, Kovanda F (2020) Structured cobalt oxide catalysts for VOC abatement: the effect of preparation method. Environ Sci Pollut Res 27:7608-7617. https://doi.org/10.1007/s11356-019-06974-2

50. Topka P, Jirátová K, Soukup K, Goliáš J (CZ308606): Device for measuring specific surface of large samples, method of measurement and its use

51. Udayabhanu MS, Kishore B, Nagabhushana H, Suresh D, Sharma SC, Nagaraju G (2017) One pot green synthesis of MnCO3-rGO composite hybrid superstructure: application to lithium ion battery and biosensor. New J Chem 41:12854-12865. https://doi.org/10.1039/c7nj01781b

52. Venkateswarlu P, Umeshbabu E, Kumar UN, Nagaraja P, Tirupathi P, Rao GR, Justin P (2017) Facile hydrothermal synthesis of urchin-like cobalt manganese spinel for high-performance supercapacitor applications. J Colloid Interface Sci 503:17-27. https://doi.org/10.1016/j.jcis.2017.05.007

53. Wang K, Cao Y, Hu J, Li Y, Xie J, Jia D (2017) Solvent-Free Chemical Approach to Synthesize Various Morphological Co3O4 for CO Oxidation. ACS Appl Mater Interfaces 9:16128-16137. https://doi.org/10.1021/acsami.7b01142

54. Wu M, Zhan W, Guo Y, Guo Y, Wang Y, Wang L, Lu G (2016) An effective Mn-Co mixed oxide catalyst for the solvent-free selective oxidation of cyclohexane with molecular oxygen. Appl Catal A 523:97106. https://doi.org/10.1016/j.apcata.2016.06.001

55. Wu S, Xie M, Zhang Q, Zhong L, Muhan C, Huang Z (2017) Isopentyl-Sulfide-Impregnated Nano$\mathrm{MnO} 2$ for the Selective Sorption of $\mathrm{Pd}(\mathrm{II})$ from the Leaching Liquor of Ores. Molecules 22:1117. https://doi.org/10.3390/molecules22071117

56. Yang X, Yu X, Jing M, Song W, Liu J, Ge M (2019) Defective MnxZr1-xO2 Solid Solution for the Catalytic Oxidation of Toluene: Insights into the Oxygen Vacancy Contribution. ACS Appl Mater Interfaces 11:730-739. https://doi.org/10.1021/acsami.8b17062

57. Zhang WD, Anguita P, Diez-Ramirez J, Descorme C, Valverde JL, Giroir-Fendler A (2020) Comparison of Different Metal Doping Effects on $\mathrm{Co}(3) \mathrm{O}(4)$ Catalysts for the Total Oxidation of Toluene and Propane. Catalysts 10. https://doi.org/10.3390/catal10080865 

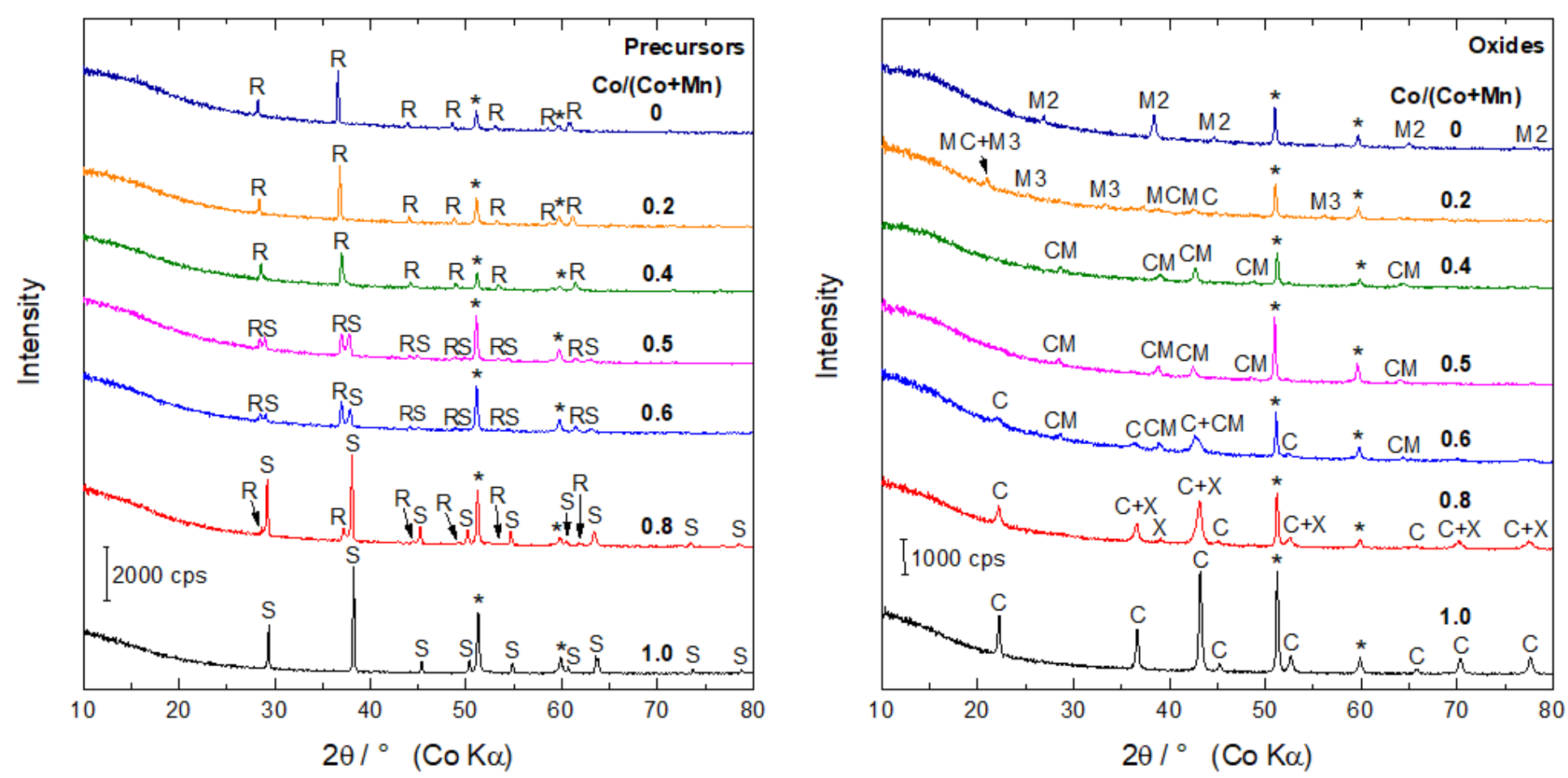

Figure 1

Powder XRD patterns of precursors and catalysts with various $\mathrm{Co} /(\mathrm{Co}+\mathrm{Mn})$ molar ratios deposited on stainless steel meshes. S - CoCO3 (spherocobaltite), R - MnCO3 (rhodochrosite), C - Co304, X Mn1.9Co1.104, CM - CoMnO3, MC - Mn2CoO4, M3 - Mn5O8, M2 - Mn2O3, * - stainless steel support.
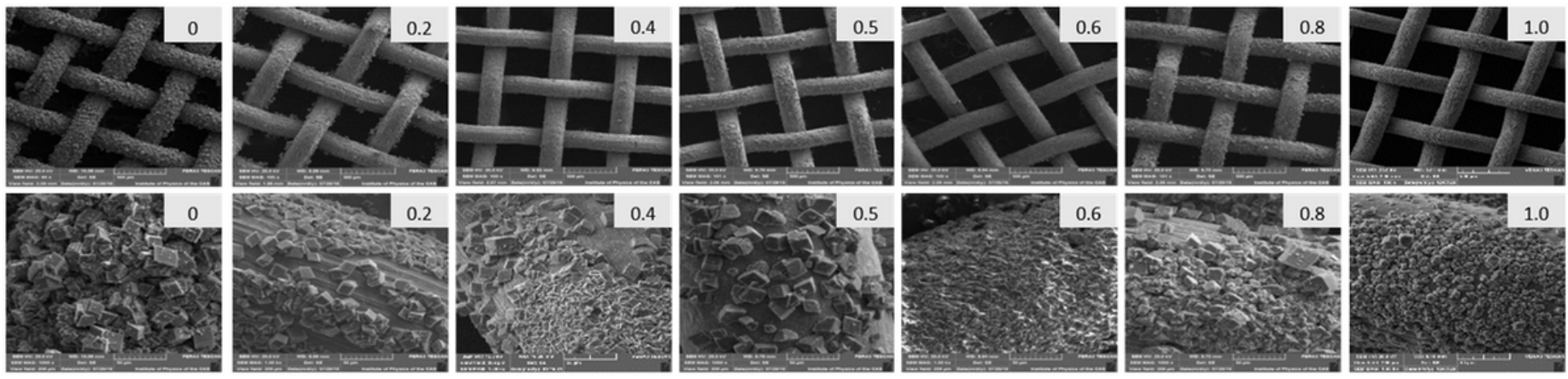

\section{Figure 2}

SEM images of catalysts with various $\mathrm{Co} /(\mathrm{Co}+\mathrm{Mn})$ molar ratiosdeposited on stainless steel meshes (upper part: magnification 100x, scale $500 \mu \mathrm{m}$, lower part: magnification $5000 x$, scale $50 \mu \mathrm{m}$ ). 


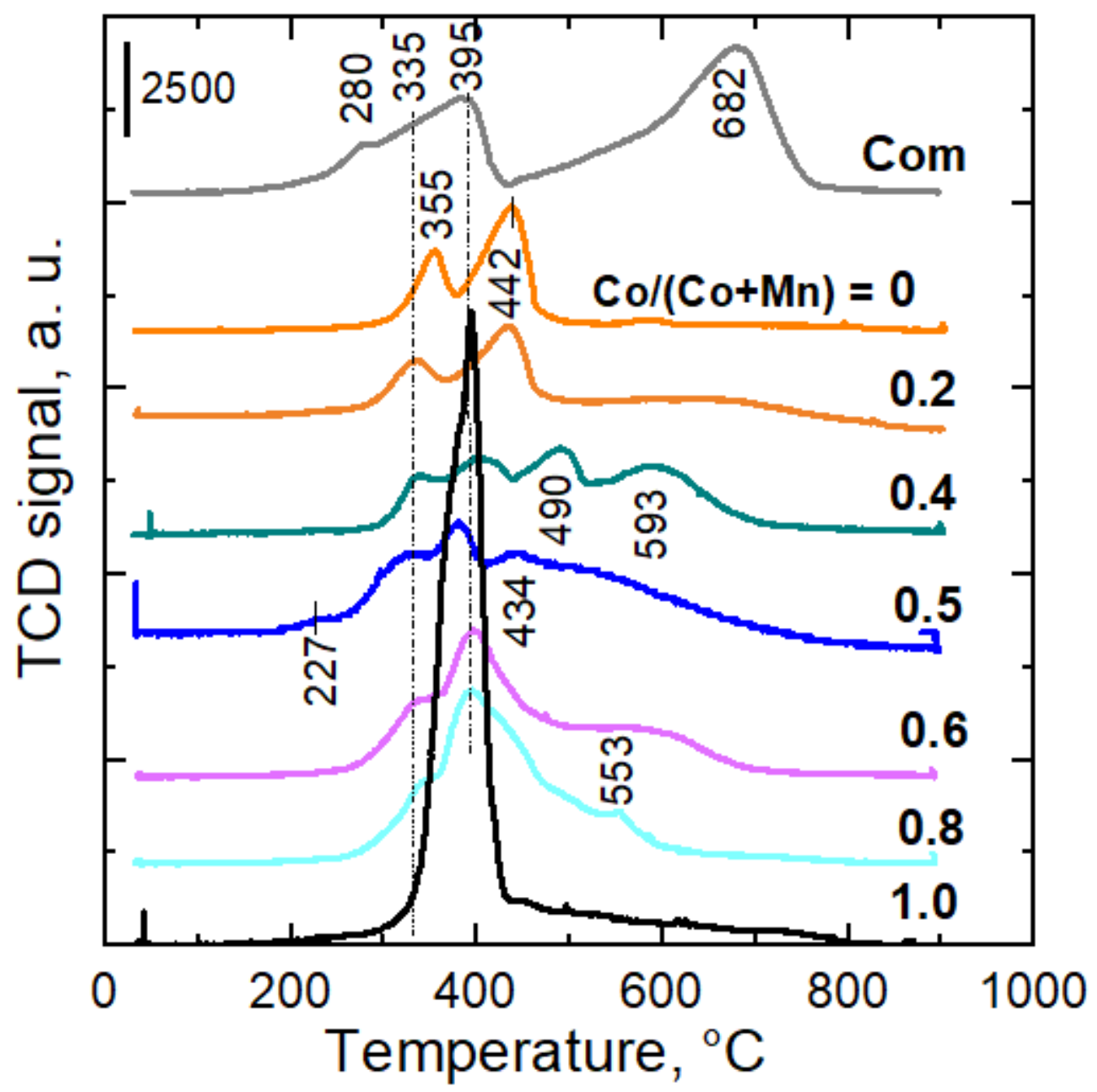

Figure 3

H2-TPR profiles of catalysts with various $\mathrm{Co} /(\mathrm{Co}+\mathrm{Mn})$ molar ratios deposited on stainless steel meshes compared to commercial Co-Mn-Al mixed oxide (Com). 


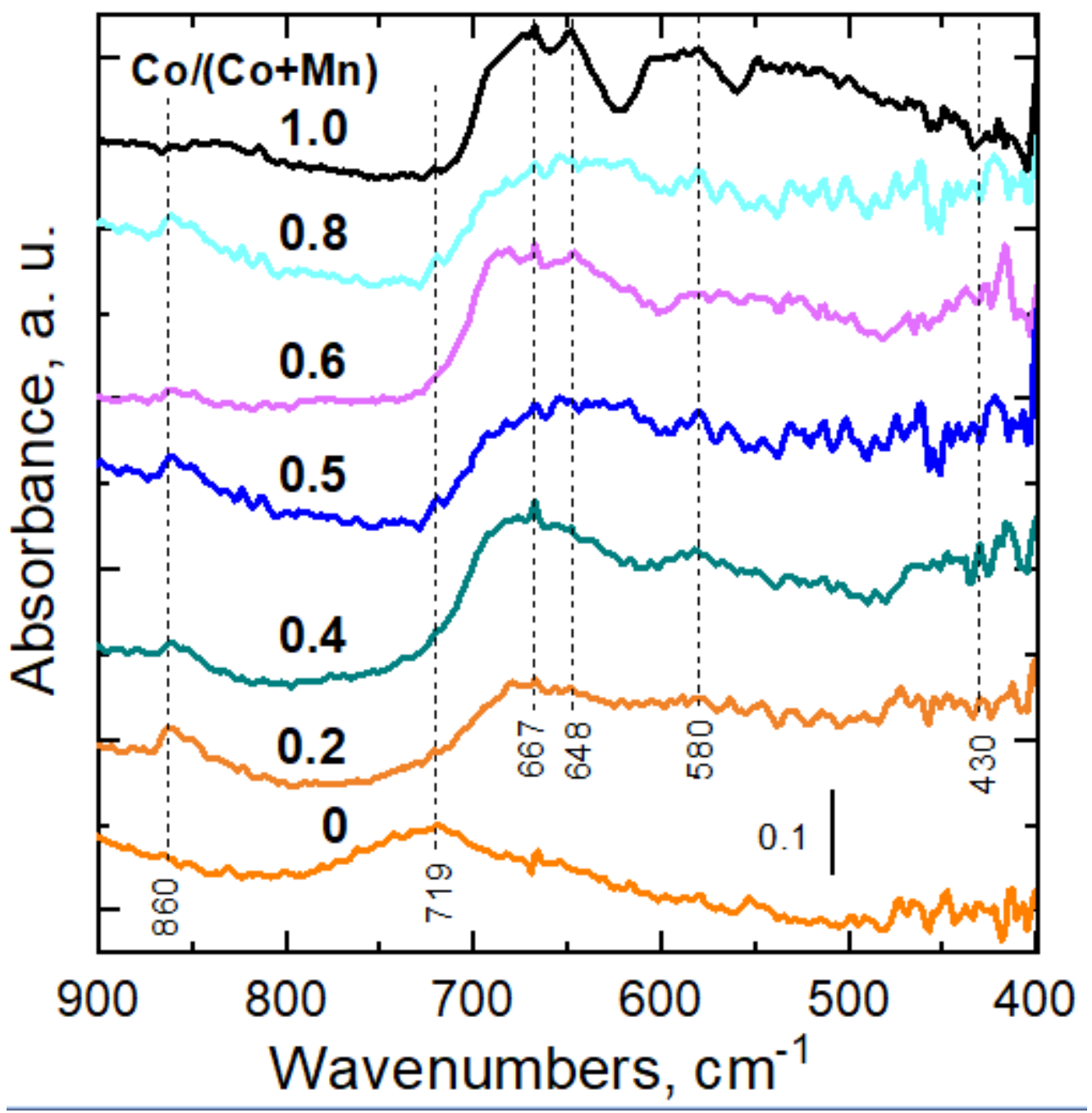

Figure 4

FTIR spectra of the catalysts with various $\mathrm{Co} /(\mathrm{Co}+\mathrm{Mn})$ molar ratios deposited on stainless steel meshes. 


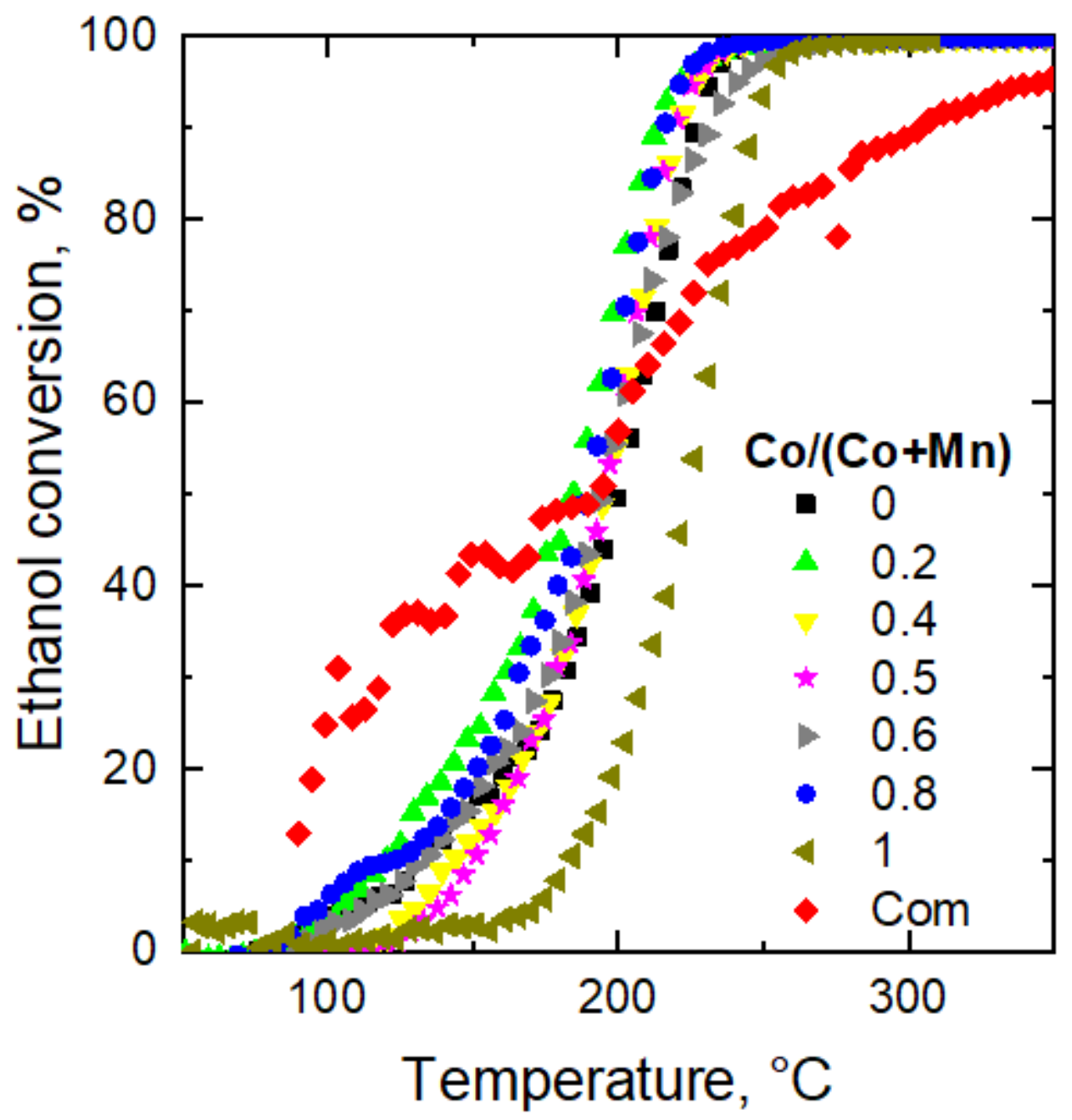

Figure 5

Light-off curves of ethanol oxidation over catalysts with various $\mathrm{Co} /(\mathrm{Co}+\mathrm{Mn})$ molar ratios deposited on stainless steel meshes compared to commercial Co-Mn-Al mixed oxide (Com). 


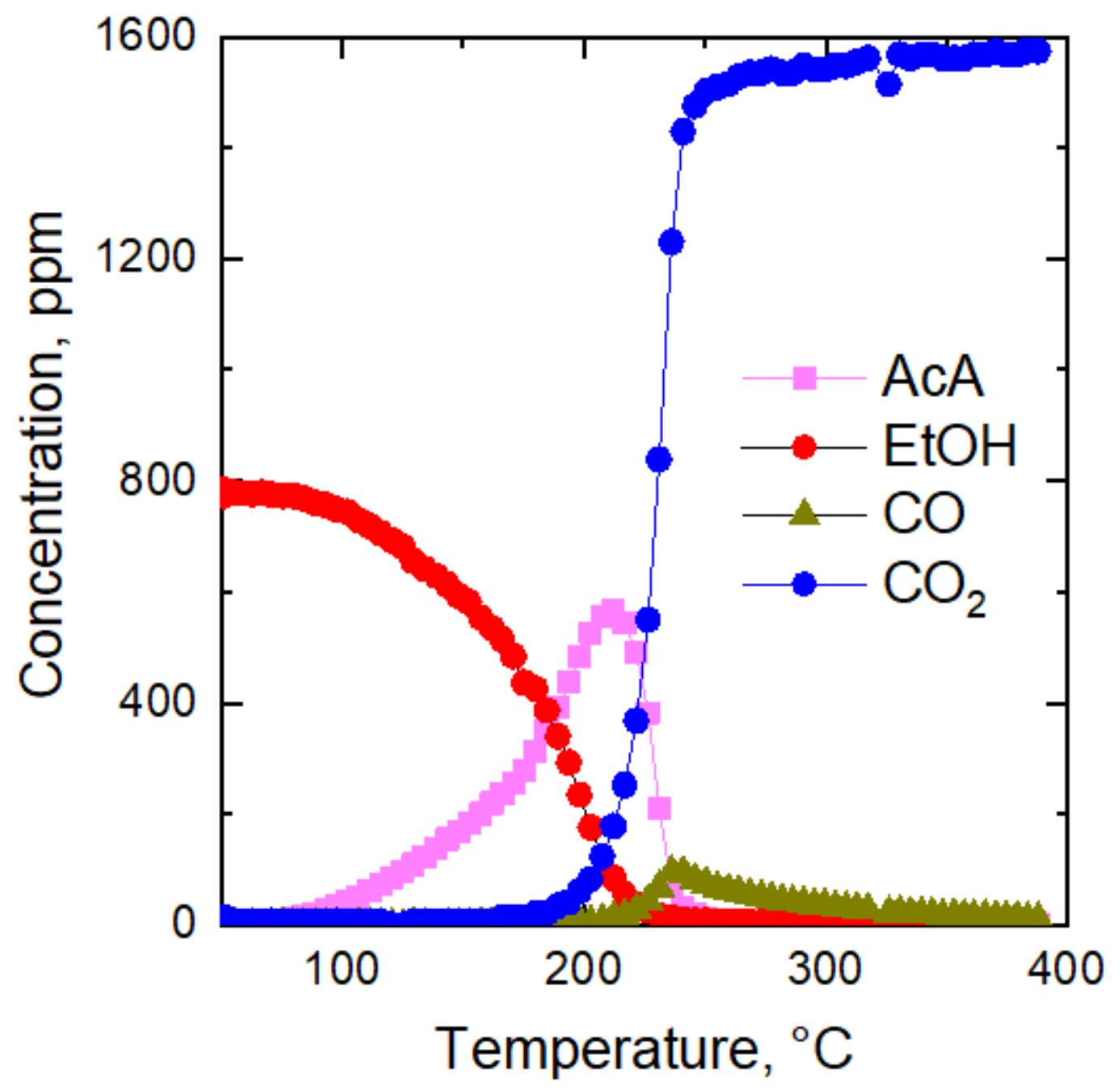

Figure 6

Dependence of ethanol (EtOH), acetaldehyde (AcA), $\mathrm{CO}$, and $\mathrm{CO} 2$ concentrations on reaction temperature during ethanol oxidation over the 0.5 catalyst. 


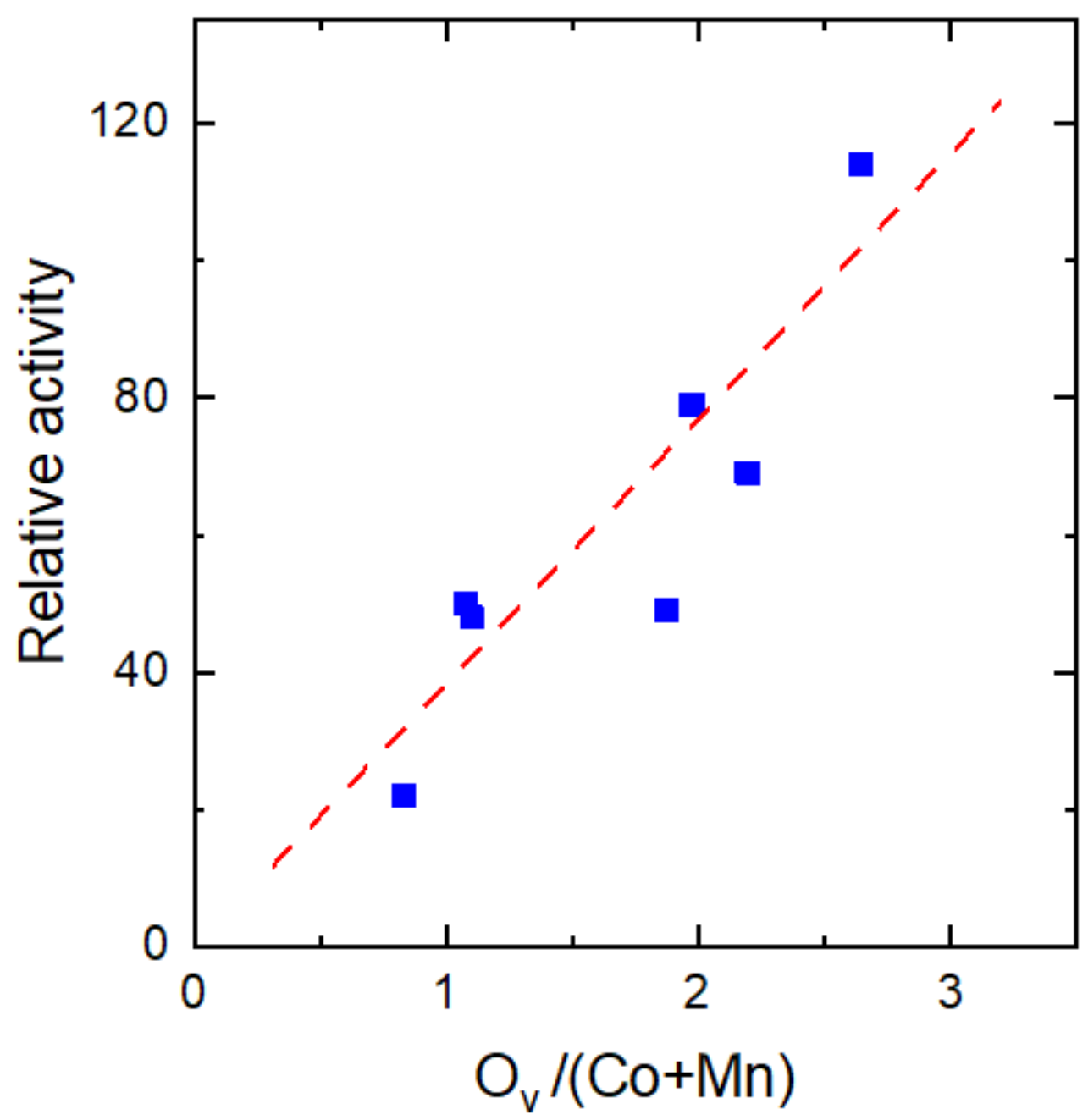

Figure 7

Dependence of relative catalytic activity on the amount of surface oxygen vacancies relative to surface Co and Mn ions as determined by XPS.

\section{Supplementary Files}

This is a list of supplementary files associated with this preprint. Click to download.

- Supplementarymaterial.docx 